\title{
Development and applications of quaternary ammonium (QA) membrane electrodes in pharmaceutical preparation and in bioavailability of Prostaglandin $\mathrm{E}_{1}$ and Deoxycholate
}

\author{
Vinod K. Gupta*, Manoj K. Pal, Ashok K. Singh \\ Department of Chemistry, Indian Institute of Technology Roorkee, Roorkee 247 667, India
}

\section{A R T I C L E I N F O}

\section{Article history:}

Received 26 February 2009

Received in revised form 10 June 2009

Accepted 12 June 2009

Available online 25 June 2009

\section{Keywords:}

Quaternary ammonium drugs

Poly (vinyl chloride) membrane electrode

Pharmaceutical analysis

Prostaglandin $\mathrm{E}_{1}$ and Deoxycholate

\begin{abstract}
A B S T R A C T
The two novel ion-pairs (PB-TPB and NB-TPB) of quaternary ammonium drugs; propantheline bromide (PB), $N, N$-Diisopropyl- $N$-methyl- $N$-[2-(xanthen-9ylcarbonyloxy)ethyl] ammonium bromide and neostigmine bromide (NB), 3-(dimethylcarbamoyloxy) phenyl]-trimethylazanium have been synthesized, respectively and incorporated in poly (vinyl chloride)-based membrane electrodes for the quantification of propantheline bromide and neostigmine bromide in different pharmaceutical preparations. The influences of membrane compositions on the potentiometric responses of membrane electrodes have been found to substantially improve the performance characteristics. The best performance was reported with membranes having composition (w/w) of PB-TPB or NB-TPB (6\%): PVC (34\%): o-NPOE (60\%). The proposed electrodes exhibit nernstian response in the concentration ranges of $2.1 \times 10^{-7} \mathrm{M}$ to $1.0 \times 10^{-2} \mathrm{M}$ and $4.4 \times 10^{-7} \mathrm{M}$ to $1.0 \times 10^{-2} \mathrm{M}$ with detection limit of $1.5 \times 10^{-7} \mathrm{M}$ and $3.3 \times 10^{-7} \mathrm{M}$, respectively. Both the membrane electrodes perform satisfactorily over $\mathrm{pH}$ ranges of (3.5-7.5 and 4.0-7.0) with fast response times (11 s and $13 \mathrm{~s}$ ), respectively. These drugs (PB and NB) were further utilized as different ion-pairs of Prostaglandin $\mathrm{E}_{1}\left(\mathrm{PGE}_{1}\right)$ and Deoxycholate $(\mathrm{DOC})$ in poly (vinyl chloride)-based membrane electrodes for the determination of bioavailability of Prostaglandin $E_{1}$ and Deoxycholate in plasma of different patients.
\end{abstract}

(c) 2009 Elsevier Ltd. All rights reserved.

\section{Introduction}

Quaternary ammonium drugs have a number of applications in medical science such as propantheline bromide (PB), $N, N$-Diisopropyl- $N$-methyl- $N$-[2-(xanthen-9ylcarbonyloxy)ethyl] ammonium bromide is an antimuscarinic [1] agent used for the treatment of excessive sweating (hyperhidrosis) [2], cramps or spasms of the stomach, intestines (gut) or bladder, and involuntary urination (enuresis) [3]. It can also be used to control the symptoms of irritable bowel syndrome and similar conditions. Similarly neostigmine bromide (NB), [3-(dimethylcarbamoyloxy) phenyl]- trimethylazanium, a cholinesterase inhibitor used in the treatment of myasthenia gravis [4-7] and to reverse the effects of muscle relaxants such as gallamine and tubocurarine. Neostigmine, unlike physostigmine, does not cross the blood-brain barrier. There are a lot of techniques for the determination of quaternary ammonium drugs in pharmaceutical preparation

* Corresponding author at (w.e.f. September 2009): Chemistry Department, King Fahd University of Petroleum and Minerals, Dhahran, Saudi Arabia. Tel.: +91 1332 285801; fax: +91 1332273560 .

E-mail addresses: vinodfcy@iitr.ernet.in, vinodfcy@gmail.com (V.K. Gupta). as propantheline drug can be assayed by HPLC [8], GC-MS [9] and homidium bromide can be assayed by ELISA [10], HPLC [11] and neostigmine bromide can be assayed by HPLC [12], ES-MS [13] and UV (as per U.S.P). In these techniques involve the use of complex procedures; several sample manipulations, require long analysis time and are not easy to automate. Development and applications of ion-selective electrodes in pharmaceutical preparation [14] analysis have enabled the direct and selective measurement of the activity of various organic cations or anions of pharmaceutical interest, in most instances without prior separation of the active substance from the formulation matrix.

To improve the analytical method for the quantitative analysis of these drugs, we developed and report the construction, performance characteristics and analytical applications of two potentiometric sensors PB-TPB and NB-TPB, based on the use of the ion-association complexes of NaTPB. These ion-association complexes show enhancement of lipophilicity and stability of drug molecules and their utility can be expressed by using them as an electroactive material in PVC based membrane sensors for the determination of their respective drug concentrations $\left(\mathrm{PB}^{+}\right.$and $\mathrm{NB}^{+}$) in the presence of excipient (coating and stabilizing) materials without separation and extraction process from pharmaceutical 
dosage (tablets and capsules) and pure drug (APIs; active pharmaceutical ingredients) forms.

\section{Experiment}

\subsection{Reagents and materials}

High molecular weight polyvinyl chloride (PVC), propantheline bromide (PB), sodium deoxycholate, Prostaglandin $\mathrm{E}_{1}$ and neostigmine bromide (NB) Aldrich (Wisconsin, USA), o-nitrophenyl octyl ether (o-NPOE) Fluka (Ronkonkoma, NY), tri-n-butylphosphate (TBP) BDH (Poole, England), chloronapthalene (CN), dibutylphthalate (DBP), sodium tetraphenylborate (NaTPB) and dibutyl(butyl) phosphonate (DBBP) Mobile (Alabama, USA).

\subsection{Preparation of ion-association complexes}

The ion-association complexes PB-TPB and NB-TPB were prepared by taking same concentration of drug ( $\mathrm{PB}$ and $\mathrm{NB}$ ) and counter ion (NaTPB) in methanol. Propantheline bromide $\left(1.0 \times 10^{-4} \mathrm{M}\right)$ and neostigmine bromide $\left(1.0 \times 10^{-3} \mathrm{M}\right)$ were separately mixed with the NaTPB having the concentrations same corresponding to drug concentration in methanol $(50 \mathrm{~mL})$ on constant stirring up to $12 \mathrm{~h}$ at $100^{\circ} \mathrm{C}$. The precipitates were formed, filtered, washed (with methanol solution) and finally dried.

PB-TPB: yield: $82 \%$, colorless, UV-vis $\left(\lambda_{\max / \mathrm{nm}}\right)(0.006 \%(\mathrm{w} / \mathrm{v})$ methanol): 246,282 . Elemental analysis \% observed was, $C=81.50$, $\mathrm{B}=1.2, \mathrm{O}=6.3, \mathrm{~N}=1.8, \mathrm{H}=6.6$ and calculated \% was $\mathrm{C}=82.0, \mathrm{~B}=1.6$, $\mathrm{O}=6.9, \mathrm{~N}=2.0, \mathrm{H}=7.2$. The observed elemental analysis is consistent with the theoretical data obtained on the basis of structure of ionpair (PB-TPB).

\subsubsection{Stoichiometry of $P B-T P B$}

The stoichiometry of the ion-pair (PB-TPB) was studied by using Job's method [15]. The concentration of propantheline bromide (PB) and NaTPB was taken to be $2.0 \times 10^{-3} \mathrm{M}$. Nine methanolic solutions were prepared containing propantheline and NaTPB in various molar ratios so that the final volume always amounted to $10 \mathrm{~mL}$ with the addition of acetate buffer $(0.05 \mathrm{M}) \mathrm{pH} 4.5$. The extraction was performed using $10 \mathrm{~mL}$ of chloroform and the absorbance was measured at $246 \mathrm{~nm}$. The plot reaches maximum value at a mole fraction $X_{\max }=0.5$ (Fig. 1), which indicates the formation of $1: 1$ ion-pair association.

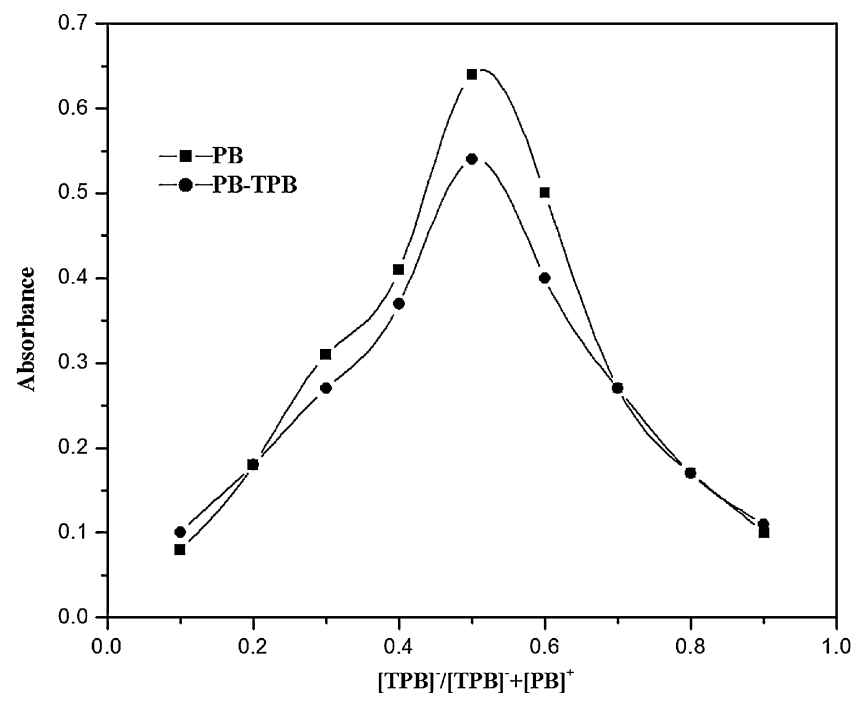

Fig. 1. Stoichiometry of ion-pair, PB-TPB by Job's curve method.

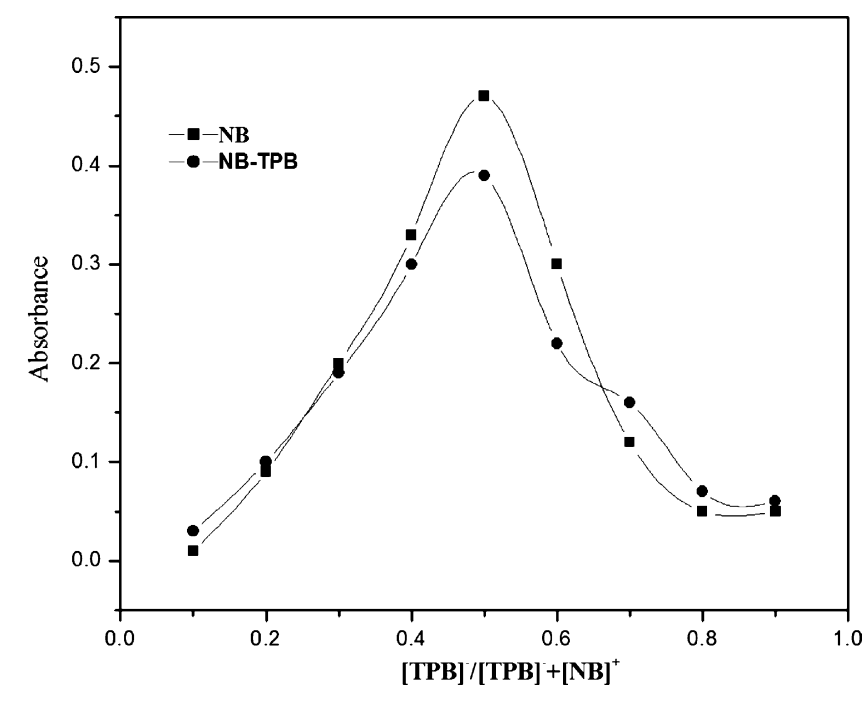

Fig. 2. Stoichiometry of ion-pair, NB-TPB by Job's curve method.

NB-TPB: yield: $78 \%$, color: red-orange, UV-vis $\left(\lambda_{\max / \mathrm{nm}}\right)(0.02 \%$ $(\mathrm{w} / \mathrm{v})$ solution in $0.5 \mathrm{M}$ sulfuric acid): 260 and 266 . Elemental analysis \% observed was, $\mathrm{C}=78.6, \mathrm{H}=6.6, \mathrm{~B}=1.9, \mathrm{O}=6.4, \mathrm{~N}=5.10$ and calculated \% was $\mathrm{C}=79.0, \mathrm{H}=7.1, \mathrm{~B}=2.0, \mathrm{O}=6.5, \mathrm{~N}=5.1$. The observed elemental analysis is consistent with the theoretical data obtained on the basis of structure of ion-pair (NB-TPB).

\subsubsection{Stoichiometry of NB-TPB}

The stoichiometry of the ion-pair (NB-TPB) was also studied by using Job's method. The concentration of neostigmine bromide (NB) and NaTPB was taken to be $2.0 \times 10^{-3} \mathrm{M}$. Nine methanolic solutions were prepared containing neostigmine bromide and NaTPB in various molar ratios so that the final volume always amounted to $10 \mathrm{~mL}$ with the addition of citrate buffer $(0.03 \mathrm{M}) \mathrm{pH}$ 7.0. The extraction was performed using $10 \mathrm{~mL}$ of acetone and the absorbance was measured at $266 \mathrm{~nm}$. The plot reaches maximum value at a mole fraction $X_{\max }=0.5$ (Fig. 2), which indicates the formation of $1: 1$ ion-pair association.

\subsection{Electrode fabrication}

The membranes have been fabricated by dissolving appropriate amounts of ion-pairs (PB-TPB and NB-TPB), PVC and plasticizers CN, DOP, $o$-NPOE in THF $(5 \mathrm{~mL})$. The components were added in terms of weight percentages. A homogenous mixture was obtained after complete dissolution of all the components, which was then concentrated by evaporating THF and then poured into polyacrylate rings placed on a smooth glass plate. The membranes of $0.4-\mathrm{mm}$ thickness were removed carefully from the glass plate and glued to one end of a "pyrex" glass tube. It is known that the sensitivity, linearity and selectivity obtained for a given ionophore depends significantly on the membrane composition and nature of plasticizer used [16]. Thus, the ratio of membrane ingredients, time of contact, concentration of equilibrating solution, etc. were optimized after a good deal of experimentation to provide membranes, which generate reproducible and stable potentials.

\subsection{Standard solution}

The standards of proposed drugs were purchased from central drug laboratory (Calcutta, India). Propantheline bromide (standard) containing not less than $90.0 \%$ and not more than $110.0 \%$ of the labeled amount of $\mathrm{C}_{23} \mathrm{H}_{30} \mathrm{BrNO}_{3}$, and similarly of neostigmine bromide (standard) containing not less than $98.0 \%$ and not more than 
Table 1

The optimization of PB-TPB and NB-TPB carrier based PVC membranes.

\begin{tabular}{|c|c|c|c|c|c|c|c|}
\hline \multirow[t]{2}{*}{ Sensor no. } & \multicolumn{3}{|c|}{ Composition of membranes (\% w/w) } & \multirow{2}{*}{$\begin{array}{l}\text { Working concentration } \\
\text { range }(\mathrm{M})\end{array}$} & \multirow[t]{2}{*}{ Detection limit (M) } & \multirow{2}{*}{$\begin{array}{l}\text { Slope } \pm 0.2 \mathrm{mV} / \\
\text { decade of activity }\end{array}$} & \multirow[t]{2}{*}{ Response time (s) } \\
\hline & Ion-pair & PVC & Plasticizer & & & & \\
\hline 1 & 0 (PB-TPB) & 36 & $64(\mathrm{DBP})$ & N.M & N.M & N.M & N.M \\
\hline 2 & 6 (PB-TPB) & 32 & 62 (DOP) & $4.4 \times 10^{-5}-1.0 \times 10^{-2}$ & $3.3 \times 10^{-5}$ & 58.6 & 16 \\
\hline 3 & 9 (PB-TPB) & 91 & 0 & $3.3 \times 10^{-3}-1.0 \times 10^{-2}$ & $2.3 \times 10^{-3}$ & 56.7 & 27 \\
\hline 4 & 6 (РB-ТРB) & 34 & $60(\mathrm{CN})$ & $3.5 \times 10^{-5}-1.0 \times 10^{-2}$ & $1.0 \times 10^{-5}$ & 58.0 & 15 \\
\hline 5 & 6 (PB-TPB) & 34 & $60(\mathrm{DBP})$ & $7.6 \times 10^{-4}-1.0 \times 10^{-2}$ & $4.3 \times 10^{-4}$ & 57.9 & 14 \\
\hline 6 & 6 (РB-TPB) & 34 & 60 (o-NPOE) & $2.1 \times 10^{-7}-1.0 \times 10^{-2}$ & $1.5 \times 10^{-7}$ & 59.3 & 11 \\
\hline 7 & 8 (PB-TPB) & 34 & 58 (o-NPOE) & $5.1 \times 10^{-7}-1.0 \times 10^{-2}$ & $4.2 \times 10^{-7}$ & 59.0 & 11 \\
\hline 8 & 10 (PB-TPB) & 30 & 60 (o-NPOE) & $6.7 \times 10^{-6}-1.0 \times 10^{-2}$ & $5.3 \times 10^{-6}$ & 58.7 & 12 \\
\hline 9 & 5 (PB-TPB) & 35 & 60 (o-NPOE) & $8.5 \times 10^{-7}-1.0 \times 10^{-2}$ & $7.8 \times 10^{-7}$ & 58.8 & 13 \\
\hline 10 & 0 (NB-TPB) & 36 & 64 (DBP) & N.M & N.M & N.M & N.M \\
\hline 11 & 6 (NB-TPB) & 32 & 62 (DOP) & $6.2 \times 10^{-5}-1.0 \times 10^{-2}$ & $5.4 \times 10^{-5}$ & 57.7 & 14 \\
\hline 12 & 9 (NB-TPB) & 91 & 0 & $4.3 \times 10^{-3}-1.0 \times 10^{-2}$ & $3.4 \times 10^{-3}$ & 56.6 & 28 \\
\hline 13 & 6 (NB-TPB) & 34 & $60(\mathrm{CN})$ & $4.3 \times 10^{-5}-1.0 \times 10^{-2}$ & $2.3 \times 10^{-5}$ & 58.3 & 17 \\
\hline 14 & 6 (NB-TPB) & 34 & $60(\mathrm{DBP})$ & $8.3 \times 10^{-4}-1.0 \times 10^{-2}$ & $5.4 \times 10^{-4}$ & 58.2 & 15 \\
\hline 15 & 6 (NB-TPB) & 34 & 60 (o-NPOE) & $4.4 \times 10^{-7}-1.0 \times 10^{-2}$ & $3.3 \times 10^{-7}$ & 59.1 & 13 \\
\hline 16 & 8 (NB-TPB) & 34 & 58 (o-NPOE) & $6.8 \times 10^{-7}-1.0 \times 10^{-2}$ & $5.2 \times 10^{-7}$ & 58.9 & 12 \\
\hline 17 & 10 (NB-TPB) & 30 & 60 (o-NPOE) & $7.4 \times 10^{-6}-1.0 \times 10^{-2}$ & $6.2 \times 10^{-6}$ & 57.8 & 18 \\
\hline 18 & 5 (NB-TPB) & 35 & 60 (o-NPOE) & $1.3 \times 10^{-6}-1.0 \times 10^{-2}$ & $8.6 \times 10^{-7}$ & 59.0 & 13 \\
\hline
\end{tabular}

N.M: not measurable.

$102.0 \%$ of $\mathrm{C}_{12} \mathrm{H}_{19} \mathrm{BrN}_{2} \mathrm{O}_{2}$, calculated on the dried basis. The standard solutions of both the drugs $\left(1.0 \times 10^{-2} \mathrm{M}\right)$ were prepared by dissolving an appropriate amount of drugs in double distilled water using acetate buffer $(0.05 \mathrm{M}) \mathrm{pH} 4.5$ and citrate buffer $(0.03 \mathrm{M}) \mathrm{pH} 7.0$ for propantheline bromide and neostigmine bromide, respectively. The working solutions of the drugs $\left(1.0 \times 10^{-8} \mathrm{M}\right.$ to $\left.1.0 \times 10^{-3} \mathrm{M}\right)$ were further prepared by simple dilution method using their respective buffers as mentioned above.

\subsection{Conditioning of membranes and potential measurements}

The electrode bodies filled with internal standard drug solutions of same concentration $\left(1.0 \times 10^{-2} \mathrm{M}\right)$ of respective drugs (PB and NB) were separately equilibrated for $24 \mathrm{~h}$ in $1.0 \times 10^{-3} \mathrm{M}$ standard drug solutions using acetate and citrate buffers for respective drugs (PB and NB) prior to potential measurements. The potential measurements were carried out at $25 \pm 1{ }^{\circ} \mathrm{C}$ using saturated calomel electrode (SCE) as reference electrode with the following cell assembly.

$\mathrm{Hg} / \mathrm{Hg}_{2} \mathrm{Cl}_{2} \mid \mathrm{KCl}$ (satd.)|0.001 M PB or NB ||PVC membrane||test solution $\left|\mathrm{Hg} / \mathrm{Hg}_{2} \mathrm{Cl}_{2}\right| \mathrm{KCl}$ (satd.)

\subsection{GC conditions}

The initial temperature $60^{\circ} \mathrm{C}$ was held for $2 \mathrm{~min}$, the temperature was programmed to $200^{\circ} \mathrm{C}$ at a rate of $20^{\circ} \mathrm{C} / \mathrm{min}$, than to $300^{\circ} \mathrm{C}$ at a rate of $30^{\circ} \mathrm{C} / \mathrm{min}$; this temperature being maintained for $1 \mathrm{~min}$. Injection port and transfer line temperatures were set at $130^{\circ} \mathrm{C}$ and $280^{\circ} \mathrm{C}$, respectively. Helium with a flow rate of $1 \mathrm{~mL} / \mathrm{min}$ was used as a carrier gas.

\section{Result and discussion}

\subsection{Optimization of membrane}

The composition of PB-TPB and NB-TPB carrier (ion-pairs) based PVC membranes were optimized by varying the ratio of ion-pairs, PVC and plasticizers to obtained membranes showing best performance regarding working concentration range, slope, detection limit and response time. It was observed that the membranes incorporating the ingredients in the ratio (w/w (\%) mg) 6 (ion-pair): 34 (PVC): 60 (o-NPOE) as shown in Table 1, displayed the best performance. The membranes without ion-pairs were also prepared and investigated that the no potentiometric response were produced. Thus it can be proved that all the potentiometric responses in the membranes were only due to the presence of ion-pairs.

\subsection{Calibration plot}

The best responsive membrane electrode sensors (nos. 6 and 15) equilibrated in $1.0 \times 10^{-3} \mathrm{M}$ drug solution using acetate $(0.05 \mathrm{M}) \mathrm{pH}$ 4.5 and citrate buffer $(0.03 \mathrm{M}) \mathrm{pH} 7.0$, respectively and potentiometrically calibrated using standard drug solutions $\left(1.0 \times 10^{-8} \mathrm{M}\right.$ to $1.0 \times 10^{-3} \mathrm{M}$ ) at $25 \pm 3^{\circ} \mathrm{C}$ with the help of $\mathrm{pH}$ meter and the obtained result shows that PB-TPB and NB-TPB carriers based membranes have detection limit of $1.0 \times 10^{-7} \mathrm{M}$ and $2.5 \times 10^{-7} \mathrm{M}$, respectively.

\subsection{Selectivity}

The selectivity coefficient $K_{\mathrm{A}, \mathrm{B}}^{\mathrm{Pot}}$ measured by separate solution method was calculated from the following equation:

$K_{\mathrm{A}, \mathrm{B}}^{\mathrm{Pot}}=\frac{E_{\mathrm{B}}-E_{\mathrm{A}}}{S}+\left[1-\frac{Z_{\mathrm{A}}}{Z_{\mathrm{B}}}\right] \log a A$

where $K_{\mathrm{A}, \mathrm{B}}^{\mathrm{Pot}}$ is the potentiometric selectivity coefficient; $E_{\mathrm{A}}$ and $E_{\mathrm{B}}$ are the potential readings observed after $1 \mathrm{~min}$ of exposing the sensor to the same concentration of $\mathrm{PB}$ or NB and interfering species $\left(1 \times 10^{-3} \mathrm{M}\right.$ each) alternatively, $a A$ the activities or concentration of $\mathrm{PB}$ or $\mathrm{NB} ; Z_{\mathrm{A}}$ and $Z_{\mathrm{B}}$ are the charges of $\mathrm{PB}$ or $\mathrm{NB}$ and interfering ions and $S$ is slope of calibration graph ( $\mathrm{mV} /$ decade of activity). The results reveal reasonable selectivity of PB-TPB (sensor no. 6) and NB-TPB (sensor no. 15) in presence of many related substances and drug stabilizing agents such as starch, lactose and sucrose is shown in Table 2.

\subsection{Effect of $p H$}

The $\mathrm{pH}$ dependence of the proposed electrodes, sensor nos. 6 and 15 were tested over the range of 3.0-8.0 for $1.0 \times 10^{-4} \mathrm{M}$ of both PB and NB separately as shown in Fig. 3 . The pH of the solution was adjusted by the addition of nitric acid or hexamine. It is clear from Fig. 2 that the useful $\mathrm{pH}$ ranges are 3.5-7.5 (sensor no. 6) and 4.0-7.0 (sensor no. 15) as the potential remains constant in these $\mathrm{pH}$ ranges. The interference in the potentials were observed below 3 or higher to $8 \mathrm{pH}$ only due to the participations of $\mathrm{H}^{+}$and $\mathrm{OH}^{-}$, respectively in 
Table 2

The selectivity of PB-TPB and NB-TPB carrier based PVC membrane electrodes in presence of interfering species.

\begin{tabular}{lll}
\hline Interfering species & \multicolumn{2}{l}{ Selectivity coefficient $\left(K_{\mathrm{A}, \mathrm{B}}^{\mathrm{Pot}}\right)$} \\
\cline { 2 - 3 } & $\mathrm{PB}-\mathrm{TPB}$ & $\mathrm{NB}-\mathrm{TPB}$ \\
\hline Deoxycholate & $1.3 \times 10^{-4}$ & $1.5 \times 10^{-4}$ \\
${\text { Prostaglandin } \mathrm{E}_{1}}_{\mathrm{Cl}^{-}}$ & $3.1 \times 10^{-4}$ & $3.6 \times 10^{-4}$ \\
$\mathrm{Br}^{-}$ & $1.5 \times 10^{-3}$ & $2.3 \times 10^{-3}$ \\
$\mathrm{CN}^{-}$ & $3.2 \times 10^{-2}$ & $3.4 \times 10^{-2}$ \\
$\mathrm{SCN}^{-}$ & $1.5 \times 10^{-2}$ & $1.7 \times 10^{-2}$ \\
$\mathrm{CH}_{3} \mathrm{COO}^{-}$ & $1.3 \times 10^{-2}$ & $1.1 \times 10^{-2}$ \\
$\mathrm{Caffeine}^{-}$ & $3.3 \times 10^{-4}$ & $3.1 \times 10^{-4}$ \\
Urea & $1.6 \times 10^{-4}$ & $1.3 \times 10^{-4}$ \\
Salbutamol sulfate & $2.1 \times 10^{-4}$ & $2.4 \times 10^{-4}$ \\
Ephedrine hydrochloride & $3.2 \times 10^{-3}$ & $3.6 \times 10^{-3}$ \\
Gelatin & $4.2 \times 10^{-3}$ & $4.6 \times 10^{-4}$ \\
Tryptophan & $2.7 \times 10^{-4}$ & $2.3 \times 10^{-4}$ \\
Starch & $2.1 \times 10^{-3}$ & $1.9 \times 10^{-3}$ \\
Lactose & $4.4 \times 10^{-4}$ & $4.1 \times 10^{-4}$ \\
Sucrose & $3.2 \times 10^{-4}$ & $2.9 \times 10^{-4}$ \\
Glucose & $1.2 \times 10^{-4}$ & $2.1 \times 10^{-4}$ \\
\hline
\end{tabular}

charge transport process of membranes, thereby causing distortion in results.

\subsection{Effect of plasticizers}

It is well known that the sensitivity and selectivity of ion-selective electrodes strongly depend on the membrane compositions and the nature of the plasticizer used [17-19]. The nature of the plasticizer influences the dielectric constant of the membrane phase, the mobility of the ionophore molecules, and the forms of the ligands [20-22]. To investigate the effect of plasticizers, PVC membranes with the different plasticizers DOP, DBP, CN and $o-\mathrm{NPOE}$ were prepared using PB-TPB and NB-TPB as the sensing membrane components. The potentiometric responses and results including slope, response time and working concentration range are summarized in Table 1. According to the data presented in Table 1, of the four different plasticizers used, $o$-NPOE is the most effective. This indicates that $o$-NPOE plasticizes the membrane, dissolves the ion-association complex, and adjusts both the membrane permittivity and the mobility of the ion-exchanger sites to give the highest possible selectivity and sensitivity [23].

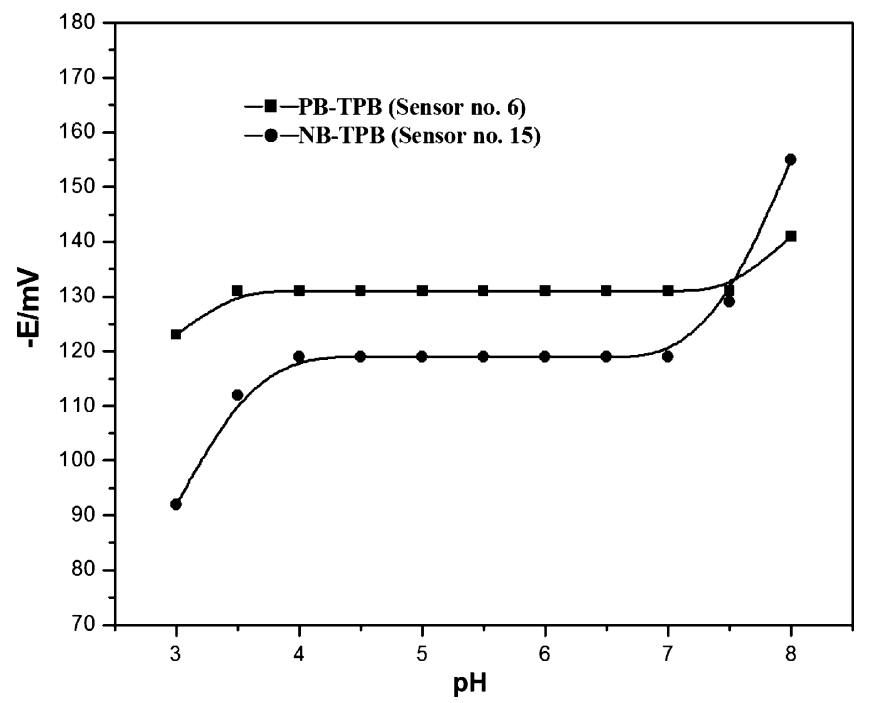

Fig. 3. Effect of $\mathrm{pH}$ on the performance of best responsive membrane electrodes (nos. 6 and 15).
Table 3

The potentiometric characteristics of the proposed sensors (sensor nos. 6 and 15).

\begin{tabular}{lll}
\hline Parameter & Proposed electrodes & \\
\cline { 2 - 3 } & Sensor no. 6(PB-TPB) & Sensor no. 15 (NB-TPB) \\
\hline Detection limit (M) & $1.5 \times 10^{-7}$ & $3.3 \times 10^{-7}$ \\
$\begin{array}{l}\text { Working concentration } \\
\text { range (M) }\end{array}$ & $2.1 \times 10^{-7}-1.0 \times 10^{-2}$ & $4.4 \times 10^{-7}-1.0 \times 10^{-2}$ \\
Slope (mV/decade of & 59.3 & \\
$\quad$ & & 59.1 \\
activity) & $3.5-7.5$ & $4.0-7.0$ \\
Working pH range & 11 & 13 \\
Response time (s) & 2.0 & 1.5 \\
Life span (months) & 0.86 & 1.10 \\
R.S.D & &
\end{tabular}

* Average of five replicates.

\subsection{Response $\left(t_{R}, s\right)$ and lifetime of the electrodes}

The electrodes, having membranes without solvent mediators gave a steady response times $\left(t_{\mathrm{R}}\right)$ of $27 \mathrm{~s}$ and $28 \mathrm{~s}$ for sensor nos. 3 and 12 , respectively whereas after adding the solvent mediators (DBP, DOP, CN and $o$-NPOE) the electrodes achieved an equilibrium response within $18-11$ s over a whole concentration range (Table 1 ). The experimental results show that the lifetime of the proposed sensors ( 6 and 15 ) were about 2 and 1.5 months, respectively. During these times, the detection limits and the slopes of the proposed sensors remained almost constant. The electrochemical behaviors of proposed sensors ( 6 and 15) gradually deteriorated after 2 and 1.5 months, which can be attributed to aging of the polymer (PVC), plasticizer and ion-pairs. All the potentiometric characteristics of proposed sensors (nos. 6 and 15) in consecutive five measurements are summarized in Table 3.

\subsection{Analytical applications}

\subsubsection{Application to pharmaceutical preparations}

The proposed sensors (nos. 6 and 15) were applied for analysis of commercial tablets of propantheline bromide $(15 \mathrm{mg})$ and neostigmine bromide ( $15 \mathrm{mg}$ ) by using standard addition method [24]. In the standard addition method, known small increments of $1.0 \times 10^{-2} \mathrm{M}$ standard drug solutions were added to $50.0 \mathrm{~mL}$ aliquots of various concentrations $\left(1.0 \times 10^{-7}-1.0 \times 10^{-3} \mathrm{M}\right)$ of pharmaceutical preparations (tablets). The changes in potentials were recorded for each increment and were used to calculate the concentration of the drug sample solution using the following equation:

$C_{\mathrm{x}}=C_{\mathrm{s}}\left(\frac{V_{\mathrm{s}}}{V_{\mathrm{x}}+V_{\mathrm{s}}}\right)\left(10^{n(\Delta E / S)}-\frac{V_{\mathrm{x}}}{V_{\mathrm{x}}+V_{\mathrm{s}}}\right)^{-1}$

where $C_{\mathrm{x}}$ and $V_{\mathrm{x}}$ are the concentration and volume of the unknown, respectively, $C_{\mathrm{S}}$ and $V_{\mathrm{S}}$ are the concentration and volume of the standard, respectively, $S$ is the slope of the calibration graph, and $\Delta E$ is the change in potential due to the addition of standards. The results are summarized in Table 4.

During analysis it was observed that both sensors (nos. 6 and 15) work well in pharmaceutical preparation measurements of most of the aqueous solutions except plasma and blood samples as some biologically active molecules (Prostaglandin $E_{1}$ and Deoxycholate) interfere with these drugs measurements.

\subsubsection{Application in bioavailability of biologically active} molecules (Prostaglandin $E_{1}$ and Deoxycholate) by ion-pairing with quaternary ammonium salts and fabricating in PVC membranes

The ion-pairs of drugs (propantheline bromide and neostigmine bromide) with biologically active molecules, Prostaglandin $E_{1}\left(P E_{1}\right)$ and Deoxycholate (DOC) were synthesized by reported 
Table 4

Determination of propantheline bromide and neostigmine bromide in pharmaceutical preparation using sensor nos. 6 and 15 , respectively.

\begin{tabular}{|c|c|c|c|c|c|}
\hline \multirow[t]{2}{*}{ Drug } & \multirow[t]{2}{*}{ Active ingredient (mg/tablet) } & \multirow[t]{2}{*}{ Sample taken (mg) } & \multicolumn{3}{|c|}{ Drug recovery ${ }^{\mathrm{a}}(\%)$} \\
\hline & & & Sensor no. 6 & Sensor no. 15 & I.Pb \\
\hline Propantheline bromide & 15 & 15.0 & $98.6 \pm 0.45$ & - & $98.0-105$ \\
\hline Neostigmine bromide & 15 & 15.0 & - & $93.2 \pm 0.65$ & $92.5-107.5$ \\
\hline
\end{tabular}

a Average of five measurements

b Indian Pharmacopoeia (1996).
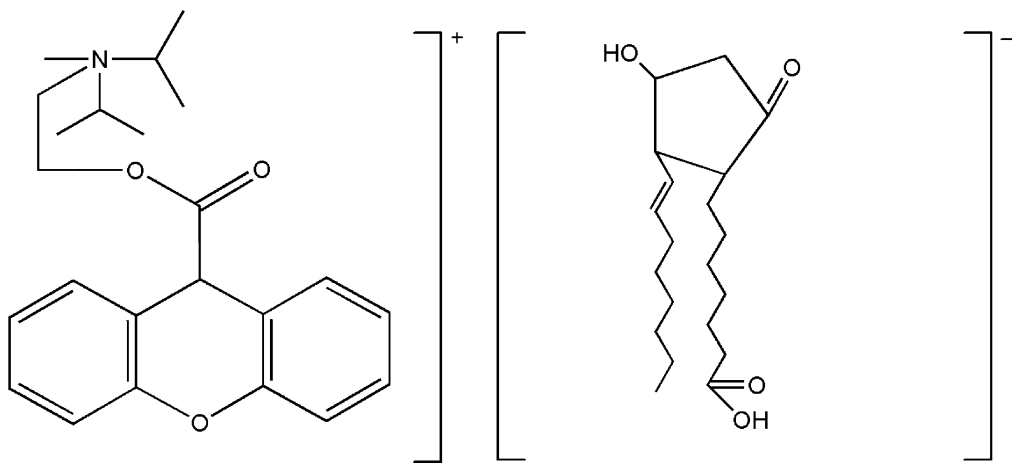

Fig. 4. Structure of $P B-P G E_{1}$.

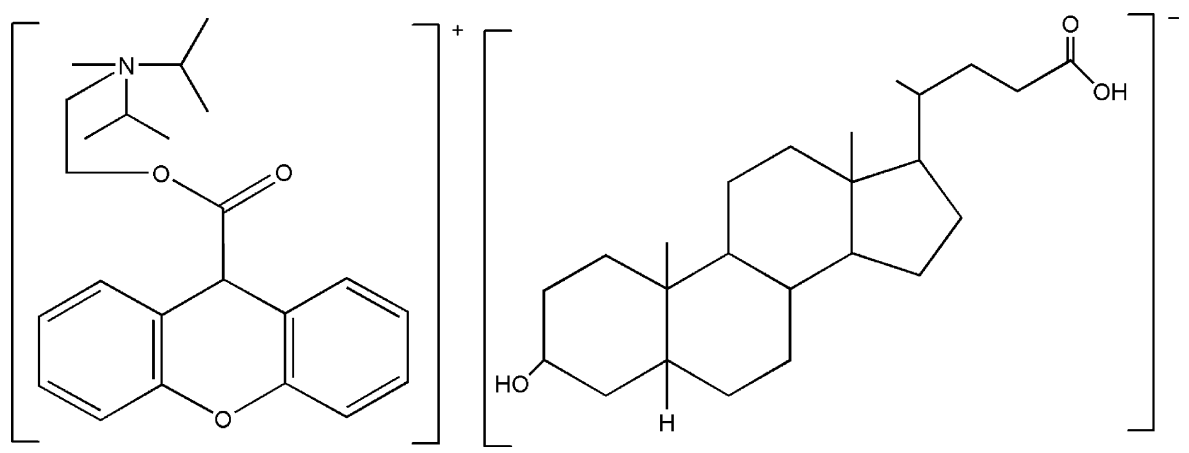

Fig. 5. Structure of PB-DOC.

method [25] and their proposed structural formulas were given in Figs. 4-7. Further scheme of synthesis was described by the following equation as in reported methods [26]:

$\mathrm{QA}_{W}^{+}+\mathrm{Y}_{W}^{-} \rightleftharpoons\left(\mathrm{QA}^{+} \mathrm{Y}^{-}\right)_{W} \rightleftharpoons\left(\mathrm{QA}^{+} \mathrm{Y}^{-}\right)_{0}$

Here the cation is a quaternary ammonium pharmacon $\left(\mathrm{QA}^{+}\right)$which interacts with the counter ion $\left(\mathrm{Y}^{-}\right)$forming a less polar ion-pair $\left(\mathrm{QA}^{+} \mathrm{Y}^{-}\right)$and for this equilibrium the $K_{\mathrm{ip}}$, the formation constant (or stability constant) of ion-pair is relevant to the following equation:

$$
K_{\text {ip }}=\frac{\left(\mathrm{QA}^{+} \mathrm{Y}^{-}\right)_{W}}{\left(\mathrm{QA}^{+}\right]_{W}\left[\mathrm{Y}^{-}\right]_{W}}
$$

The distinct and thermodynamically stable species $\left(\mathrm{QA}^{+} \mathrm{Y}^{-}\right)$formed partitions between the aqueous $(w)$ and organic phases $(0)$ which equilibrium can be characterized by the (true) partition coefficient $(P)$ of the ion-pair (Eq. (5)). The related other equilibrium constants<smiles></smiles>
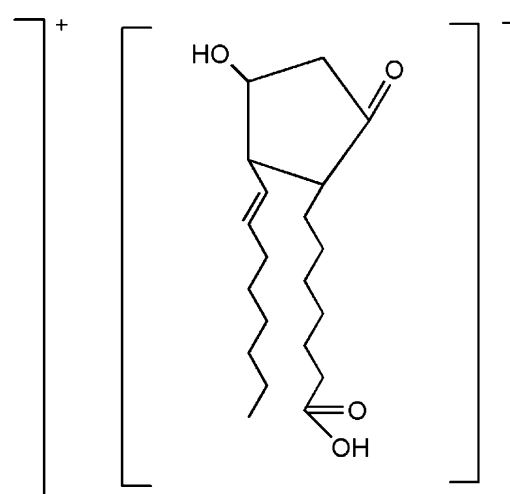

Fig. 6. Structure of NB-PGE 


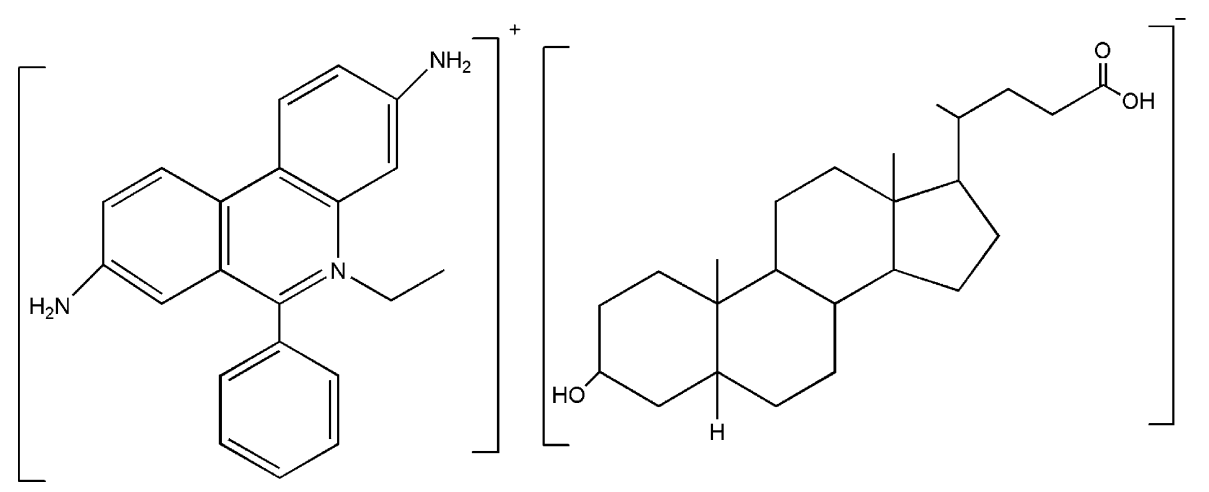

Fig. 7. Structure of NB-DOC.

(apparent partition coefficient of the ion-pair, $P^{\prime}$, and that of cation, $P_{\mathrm{QA}^{\prime}}$; extraction constant, $\left.K_{\mathrm{ex}}\right)$ and their relationships are summarized in the following equations.

$P=\frac{\left(\mathrm{QA}^{+} \mathrm{Y}^{-}\right)_{0}}{\left(\mathrm{QA}^{+} \mathrm{Y}^{-}\right)_{w}}$

$$
P^{\prime}=\frac{\left(\mathrm{QA}^{+} \mathrm{Y}^{-}\right)}{\left[\mathrm{QA}^{+}\right]_{w}+\left(\mathrm{QA}^{+} \mathrm{Y}^{-}\right)_{w}}
$$

$P_{\mathrm{QA}+}{ }^{\prime}=\frac{\left(\mathrm{QA}^{+} \mathrm{Y}^{-}\right)_{0}}{\left[\mathrm{QA}^{+}\right]_{w}}$

$$
K_{\mathrm{ex}}=\frac{\left(\mathrm{QA}^{+} \mathrm{Y}^{-}\right)_{0}}{\left[\mathrm{QA}^{+}\right]_{w}\left[\mathrm{Y}^{-}\right]_{w}}
$$

$$
\log K_{\mathrm{ex}}=\log P^{\prime}-\log \left[\mathrm{Y}^{-}\right]_{w}
$$

$\log P=\log K_{\mathrm{ex}}-\log K_{\mathrm{tp}}$

All these equations describe how the partition coefficient is related to the stability constant and it was concluded that the existence of ion-pairs even in aqueous solutions which may emerge when ions involved are relatively hydrophobic. It has also been established in the formation of such type of ion-pairs, out of the electrostatic forces other interactions, e.g. hydrophobic and polar ones, also play significant role. The $\log P$ values of quaternary ammonium drugs (QA) in bromide salt form as used in medicine (without external counter ions), were determined by shake-flask technique in order to describe the "intrinsic" lipophilicity of these molecules. The QA salts according to their molar absorptivity, were dissolved in the mixture of 1:20 (water/octanol) and absorbance was taken at their characteristic $\lambda_{\max }$ ( 246 for PB and 266 for NB) and $\log P$ values were determined by the following equation:

$\log p^{\prime}=\frac{A_{o}-A_{w}}{A_{w}} \frac{V_{w}}{V_{o}}$

where $A_{o}$ and $A_{w}$ are absorbance in aquoeous before and after partitions, from this equation other parameters also calculated as discussed in above coorelated equation and results were summarized in Table 5 . It was observed that both the compounds have very low lipophilicity and will have very low significant active concentration in blood particularly of neostigmine bromide. To overcome this problem an ion-pair method was selected to increase the lipophilicity and similarly $\log P$ values of some selected biologically active molecules were also determined to find out the suitable ion-pairing molecules and results were compiled in Table 5. It was observed that Deoxycholate and Prostaglandin $\mathrm{E}_{1}$ have maximum lipophilicity in comparison to others, therefore by keeping this view in mind a different approach of PVC based sensor was utilized to determine the bioavailability of these two biologically active molecules having many biological applications in the body.
Table 5

Lipophilicity of quaternary ammonium drugs (QA).

\begin{tabular}{lc}
\hline Quaternary ammonium drug $(\mathrm{QA})$ & $\log p( \pm \mathrm{S} . \mathrm{D})^{\mathrm{a}}$ \\
\hline $\begin{array}{lc}\text { Propantheline bromide } \\
\text { Neostigmine bromide }\end{array}$ & $-1.11(0.04)$ \\
& $<-3.5(0.03)$ \\
Biologically active molecule & $\log P( \pm \mathrm{S} . \mathrm{D})$ \\
\hline Deoxycholate & $3.62(0.04)$ \\
Prostaglandin $\mathrm{E}_{1}$ & $3.17(0.06)$ \\
Caproate & $2.01(0.03)$ \\
Nicotinate & $1.12(0.04)$ \\
Hydrogen-fumarate & $0.54(0.04)$ \\
Hydrogen maleate & $0.18(0.05)$ \\
Acetate & $-0.15(0.02)$ \\
P-toluenesulfonate & $-0.65(0.06)$ \\
Pyruvate & $-1.20(0.03)$ \\
Mesylate & $-2.31(0.03)$ \\
\hline
\end{tabular}

a Measurement of three replicates at 1:20 (water/octanol).

3.7.2.1. Effect of counter ions on the lipophilicity of QAs. The effect of counter ions (Prostaglandin $\mathrm{E}_{1}$ and Deoxycholate) on the lipophilicity of QAs (propantheline bromide and neostigmine bromide) were studied under different $\mathrm{QA}^{+} / \mathrm{Y}^{-}$molar ratios and it was observed that maximum lipophilicity of QAs was observed at 1:50 molar ratio (Figs. 8 and 9) and it was concluded that PGE $_{1}$ and DOC have maximum lipophilicity and ion-pairing ability effect on both the QAs. The analysis of the enhancement in lipophilicity suggests that the size of the counter ion may be a determining factor.

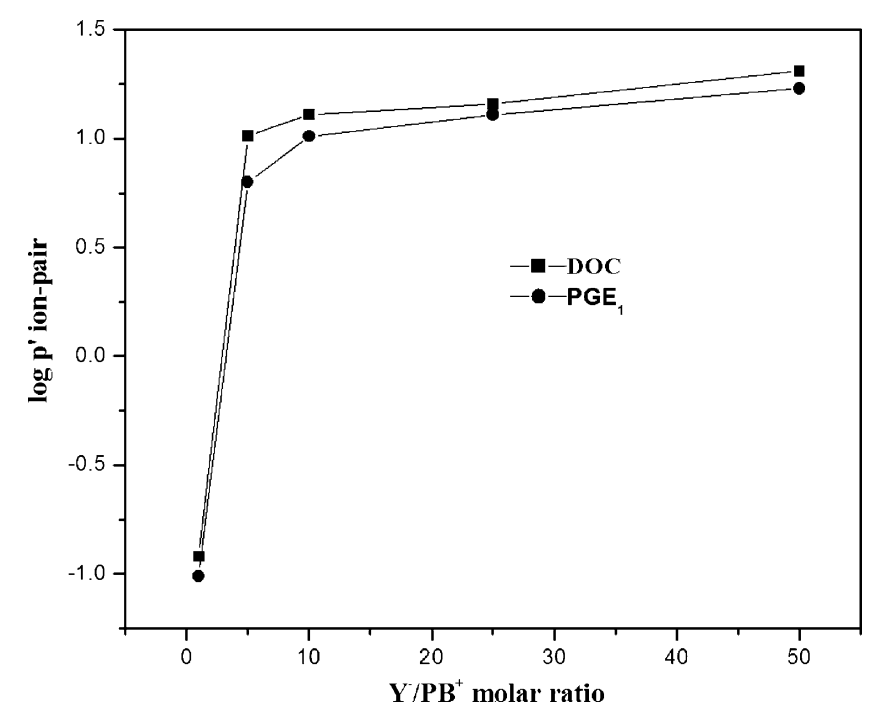

Fig. 8. Effect of counter ions $\left(\mathrm{PGE}_{1} \& \mathrm{DOC}\right)$ on the lipophilicity of propantheline bromide. 
Table 6

Determination of bioavailability of Prostaglandin $E_{1}$ and Deoxycholate in blood plasma of different patients.

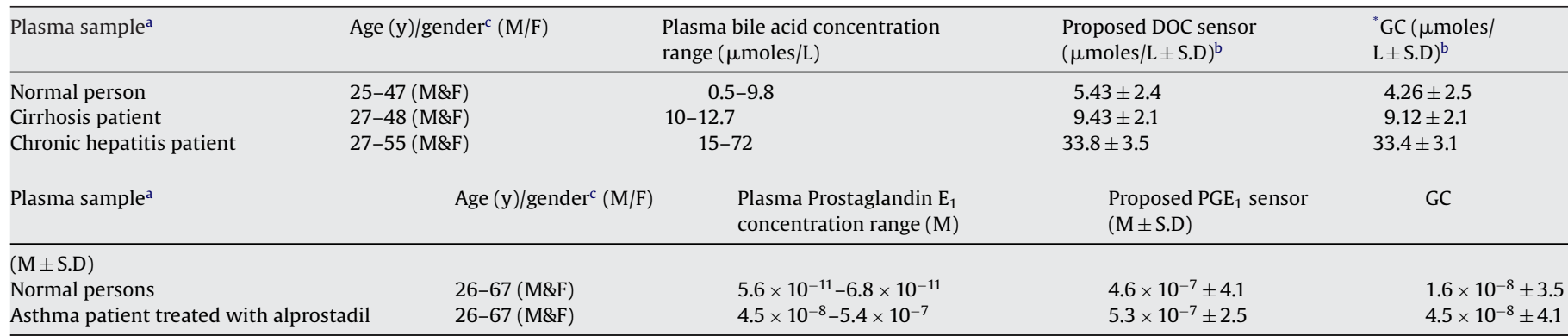

\footnotetext{
a Samples collected from 25 patients.

b \pm Standard deviation.

c $\mathrm{M}$ (male), $\mathrm{F}$ (female).

${ }^{*}$ GC conditions: initial temperature: $60^{\circ} \mathrm{C}$; final temperature: $300^{\circ} \mathrm{C}\left(30^{\circ} \mathrm{C} / \mathrm{min}\right)$; carrier gas: $\mathrm{He}(1 \mathrm{~mL} / \mathrm{min})$.
}

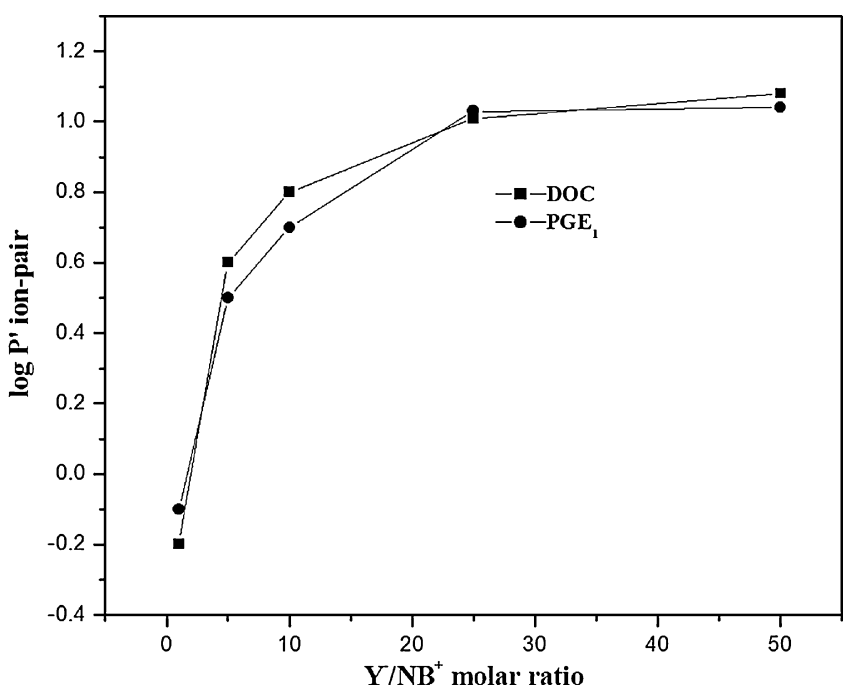

Fig. 9. Effect of counter ions $\left(\mathrm{PGE}_{1} \& \mathrm{DOC}\right)$ on the lipophilicity of neostigmine bromide.

3.7.2.2. Fabrication of membranes. Different membranes were fabricated by dissolving different amounts of plasticizers, PVC and ion-pairs and membranes were optimized as mentioned above and it was observed that membranes with $\operatorname{PVC}(30)$ : $o-\operatorname{NPOE}(60)$ : QA-PGE 1 (10) and PVC(30): o-NPOE(60): QA-DOC(10) (w/w) ratio show best performance characteristics. The standard solutions $\left(5.0 \times 10^{-8}-1.0 \times 10^{-2}\right)$ of $\mathrm{PGE}_{1}$ and DOC were prepared by using phosphate buffer $\left(\mathrm{H}_{2} \mathrm{PO}_{4}^{-}\right.$and $\mathrm{HPO}_{4}^{-2}$, $\left.\mathrm{pH} 6.5\right)$

3.7.2.3. Bioavailability of $P G E_{1}$ and DOC. The bioavailability of Prostaglandin $\mathrm{E}_{1}$ and Deoxycholate in blood was determined by collecting the blood samples of different patients from near city hospital and centrifuge at $8000 \mathrm{rpm}$ to remove the cell debris and obtained plasma can be directly diluted $\left(5 \times 10^{-8}-1.0 \times 10^{-2} \mathrm{M}\right)$ by using phosphate buffer $\left(\mathrm{H}_{2} \mathrm{PO}_{4}^{-}\right.$and $\left.\mathrm{HPO}_{4}{ }^{-2}, \mathrm{pH} 6.5\right)$ and may stored in refrigerator by adding small amount of sodium citrate solution, if measurement was to be done latter (not exceeding four days). Both the membrane electrodes; PVC(30): o-NPOE(60): QA-
$\mathrm{PGE}_{1}$ (10) and PVC(30): o-NPOE(60): QA-DOC(10) were equilibrated for two days in $1.0 \times 10^{-2} \mathrm{M}$ standard solution of Prostaglandin $\mathrm{E}_{1}$ and Deoxycholate, respectively and potentiometric responses were studied out against the diluted plasma solutions and results comparatively with GC data were compiled in Table 6 .

\section{Acknowledgement}

One of the authors Manoj Kumar Pal is thankful to Ministry of Human Resource Development (MHRD), New Delhi, India, for financial support.

\section{References}

[1] J.C.L. Yu, R.J. Sung, Cardiovasc. Drugs Ther. 10 (1997) 687.

[2] L.P. Stolman, Dermatol. Clin. 16 (1998) 863.

[3] A.J. Wein, Urology 51 (1998) 43.

[4] A. Agbe, K.L. Yielding, J. Parasitol. 81 (1995) 968.

[5] D. Steverding, Parasites Vectors 1 (2008) 1756.

[6] K.D. Beck, F.X. Brennan, R.L. Moldow, J.E. Ottenweller, G. Zhu, R.J. Servatius, Life Sci. 73 (2003) 41.

[7] K. Chan, A. Dehchan, J. Pharmacol. Method 1 (1978) 311.

[8] B.G. Charles, P.J. Ravenscroft, J. Pharm. Sci. 72 (2006) 96.

[9] C.W. Vose, G.C. Ford, S.J.W. Grigson, N.J. Haskins, M. Prout, P.M. Stevens, D.A Rose, R.F. Palmer, Br. J. Clin. Pharmacol. 7 (1979) 89.

[10] G.A. Murilla, M.C. Eisler, A.S. Peregrine, J.M. Ndung'u, P.H. Holmes, J. Vet. Pharmacol. Ther. 22 (2002) 301.

[11] J.N.A. Tettey, G.G. Skellern, J.M. Midgley, M.H. Grant, R. Wilkinson, A.R. Pitt, Xenobiotica 29 (1999) 349.

[12] F. Varin, J. Couture, Gaoh. J. Chromatogr. 723 (1999) 319

[13] A.R. Hind, S.K. Bhargava, P.G. Cullis, Anal. Chim. Acta 377 (1998) 39.

[14] F.M. Abdel-Gawad, J. Pharm. Biomed. Anal. 16 (1998) 793.

[15] A. Nezhadali, H.A. Hosseini, P. Langara, Eur. J. Chem. 4 (2007) 581

[16] T. Katsu, K. Ido, K. Takaishi, H. Yokosu, Sens. Actuators B 87 (2002) 331.

[17] E. Bakker, P. Buhlmann, E. Pretsch, Electroanalysis 11 (1999) 915.

[18] E. Ammann, P. Pretsch, W. Simon, E. Lindner, A. Bezegh, E. Pungor, Anal. Chim. Acta 171 (1991) 1380.

[19] E. Bakker, P. B“uhlmann, E. Pretsch, Chem. Rev. 97 (1997) 3083.

[20] X. Yang, N. Kumar, H. Chi, D.D. Hibbert, P.N.W. Alexander, Electroanalysis 9 (1997) 549.

[21] R. Eugster, T. Rrosatzin, B. Rusterholz, B. Aebersold, U. Pedrazza, D. Ruegg, A Schmid, U.F. Spichiger, W. Simon, Anal. Chim. Acta 289 (1994) 1

[22] M.R. Ganjali, P. Norouzi, T. Alizadeh, M. Adib, Anal. Chim. Acta 576 (2006) 275.

[23] V.K. Gupta, A.K. Singh, S. Mehtab, B. Gupta, Anal. Chim. Acta 566 (2006) 5.

[24] E. Baumann, Anal. Chim. Acta 42 (1968) 127.

[25] R.M. Diamond, J. Phys. Chem. 67 (1963) 2513.

[26] K.T. Novak, G. Szask, Pharm. Res. 16 (1999) 1633. 